\title{
A Economia da Religião e seus Fundamentos: Teste de um Modelo de Escolha Religiosa
}

\author{
Lívio Luiz Soares de Oliveira - Renan Xavier Cortes - Giácomo Balbinotto Neto
}

Submetido: 28 de julho de 2010; aceito para publicação: 25 de julho de 2011

Resumo: O objetivo deste trabalho é expor, com base na literatura de Economia da Religião, a premissa de racionalidade humana relacionada ao comportamento religioso. Serão abordados conceitos e definições da Economia da Religião, o objeto de interesse dessa disciplina, isto é, as questões com as quais se preocupa, além de discutir-se, sucintamente, a origem e a evolução da Economia da Religião. Discutem-se dois dos fundamentos teóricos da Economia da Religião: a Escolha Racional e a Teoria do Consumidor aplicada à religião. Como contribuição empírica, realizou-se um teste de um modelo de escolha religiosa empregando a técnica de Análise de Discriminante. Por último, serão discutidas as vantagens, objeções e críticas relativas à Teoria da Escolha Racional Religiosa.

Palavras-Chave: religião, economia da religião, escolha racional

Abstract: This paper aim, based on the literature of Economics of Religion, to the premise of human rationality related to religious behavior. Are discussed concepts and definitions of the Economics of Religion, the object of interest in this discipline, ie, the most important issues, and discuss briefly the origin and evolution of disci-

Lívio Luiz Soares de Oliveira

Doutor em Economia DSc - FEE - Fundação de Economia e Estatística Siegfried Emanuel Heuser - Endereço para contato: Rua Duque de Caxias, 1691 - Porto Alegre - RS CEP 90010-283 - Porto Alegre - RS - Email: Lívio@fee.tche.br/livioluiz@hotmail.com

Renan Xavier Cortes

Pesquisador e Estatístico da FEE - Fundação de Economia e Estatística Siegfried Emanuel Heuser - Endereço para contato: Rua Duque de Caxias, 1691 - CEP 90010-283 - Porto Alegre - RS - Email: renan@fee.tche.br

Giácomo Balbinotto Neto

Doutor em Economia - DSc - Programa de Pós Graduação em Economia Aplicada (PPGE) da Universidade Federal do Rio Grande do Sul (UFRGS) - Endereço para contato: Av. João Pessoa, 52 sala 33-B - Centro - Porto Alegre - RS - CEP 90040-000 - Email: giacomo. balbinotto@ufrgs.br 
pline. Rational Choice and Consumer Theory applied to the Religion, two of the theoretical fundamentals of Economics of Religion are discussed. As an empirical contribution, we carried out a test of a model of religious choice employing the technique of Discriminant Analysis. Finally, we discuss the advantages, objections and criticisms regarding the Rational Choice Theory of Religion.

Keywords: religion, economics of religion, rational choice

JEL Classification: D1 1, Z12

\section{Introdução}

A Economia da Religião é uma disciplina que tem como objetivo a explicação do comportamento religioso dos seres humanos a partir da Teoria da Escolha Racional. A Escolha Racional pode ser definida como aquela que maximiza a utilidade de um indivíduo, de acordo com os seus objetivos. O comportamento religioso pode ser definido como aquele adotado pelo indivíduo por meio de ritos, práticas devocionais, penitências, etc., para alcançar seus objetivos com base em suas crenças religiosas.

Dessa forma, a Economia da Religião difere de outras abordagens que procuram estudar a religião cientificamente. No caso da Sociologia, Psicologia e Antropologia da Religião, por exemplo, as suas abordagens para estudar o comportamento religioso humano têm por base premissas diferentes daquelas da Escolha Racional e tendem a enfatizar questões distintas.

Diferentemente da Tese da Secularização, por exemplo, a qual afirma que as mudanças religiosas são respostas a alterações do lado da demanda como resultado da variação de gostos, preferências, tendências histórico-culturais, a Teoria da Escolha Racional sustenta o oposto, isto é, afirma que as mudanças religiosas originam-se nas alterações da oferta religiosa. Essas alterações estariam relacionadas, principalmente, ao grau de regulação do mercado religioso pelo governo, o que iria se refletir na pluralidade e na magnitude da competição religiosa existente entre os produtores de religião nesse 
mercado. Já a demanda seria caracterizada pela estabilidade das preferências religiosas. Com esse enfoque, a Escolha Racional inverteu o eixo de estudo científico da religião, nas Ciências Sociais, do lado da demanda para o lado da oferta religiosa, passando a ser chamada de o "Novo Paradigma" (ver Warner, 1993).

Tanto sociólogos, psicólogos e antropólogos, principalmente aqueles que são adeptos da tese da secularização, tendem a ver a religião como um comportamento irracional ou reflexo de uma mente primitiva do ser humano, principalmente por causa de trabalhos de autores que se tornaram clássicos, como Comte (2000 [1896]), Durkheim (2001) e Freud (2006 [1927]).

A abordagem da Economia da Religião não exclui a possibilidade de secularização, mas o seu método de estudo do comportamento religioso enfoca esta temática sob um ponto de vista particular. Um dos seus conceitos fundamentais é o de commodity religiosa, a qual nada mais é, segundo Iannaccone (1992, p.124), que um termo designado para identificar a religião como um objeto de escolha, envolvendo bens e serviços religiosos passíveis de serem produzidos e consumidos pelos agentes inseridos no mercado religioso.

Conforme Iannaccone (1992, p. 125), uma commodity religiosa não é um bem físico como um automóvel ou um computador, os quais podem ser fabricados e vendidos em lojas. Nem representa um serviço como um corte de cabelo ou um atendimento bancário. Citando Becker (1976, p.125), Iannaccone afirma que as commodities religiosas podem ser classificadas na categoria de commodities domésticas, as quais representam bens e serviços que os indivíduos e famílias produzem para o seu próprio consumo. Podem ser concretas e abstratas. Exemplos de commodities domésticas concretas: CDs e DVDs religiosos, textos considerados sagrados (Bíblia, Torá, Alcorão) e livros religiosos. Exemplos de commodities abstratas: meditação, oração e felicidade decorrente da prática religiosa. De modo idêntico às commodities seculares, as commodities religiosas também são produzidas com recursos escassos - tempo, dinheiro, trabalho e habilidades intelectuais.

Iannaccone (1992, p.125) apontou os méritos e as vantagens da análise da prática religiosa sob a perspectiva do conceito de commodity doméstica. Essa análise procura explicar padrões observados de mu- 
dança denominacional, casamento inter e intrarreligioso, padrões de conversão, relações entre frequência religiosa e doações, a influência da educação religiosa sobre o nível de frequência a serviços religiosos e sobre escolhas de casamento, dentre outras questões.

Nesta introdução foram abordados conceitos e definições da Economia da Religião. Na segunda seção será discutido o objeto de interesse dessa disciplina, isto é, o conjunto de questões com as quais se preocupa. A seção seguinte trata da origem e da evolução da Economia da Religião. Essas seções constituem-se como etapa de discussão necessária antes que sejam apresentados e comentados, logo depois, na seção quatro, os fundamentos da Economia da Religião. Nesta seção, será feito um teste econométrico da Escolha Racional e da Teoria do Consumidor, relativamente ao comportamento religioso individual, com uso da técnica estatística de Análise de Discriminante, complementada préviamente pela Análise de Componentes Principais. Para realizar o teste foram utilizados os dados da Pesquisa Social Brasileira de 2004. Finalizando, serão comentadas as vantagens, objeções e críticas relativas à Teoria da Escolha Racional Religiosa.

\section{Objeto de Interesse da Economia da Religião}

A Economia da Religião está interessada em responder uma série de questões, entre as quais estão, por exemplo:

- Como as pessoas produzem commodities religiosas e como estas podem ser diferenciadas das commodities seculares?

-Por que as commodities religiosas são, de modo geral, produzidas e consumidas coletivamente?

-Por que as commodities religiosas não são, em diversas situações, negociadas monetariamente?

-Quais são os custos diretos e indiretos de diferentes religiões e de diferentes práticas religiosas? 
Essas e outras são algumas das questões com as quais a Economia da Religião se preocupa em responder. É importante também salientar que a Economia da Religião é distinta da chamada Economia Religiosa. Enquanto a primeira tem como objetivo a explicação do comportamento religioso humano, tendo como base as premissas econômicas, a segunda toma a sua autoridade de escritos considerados sacros, como a Bíblia Sagrada, a Torá e o Alcorão para justificar ou criticar o comportamento econômico. A Economia da Religião, que pode ser compreendida como um empreendimento de cunho positivo, isto é, que procura explicar como o comportamento religioso é, e não como deveria ser, transporta princípios da economia para explicar a religião. Por outro lado, a Economia Religiosa, que pode ser entendida como um empreendimento normativo, ao contrário da Economia da Religião, transporta princípios das religiões para explicar a economia e procura mostrar como esta deveria ser com base na interpretação de princípios religiosos. Seus principais estudiosos são filósofos, teólogos e economistas, cujo principal interesse é avaliar o impacto de políticas econômicas à luz dos preceitos religiosos. $\mathrm{Na}$ próxima seção serão discutidas as origens e a evolução da Economia da Religião.

\section{Origens e Evolução da Economia da Religião}

Desde que Adam Smith analisou as implicações econômicas do grau de concentração do mercado religioso em A Riqueza das Nações, publicado em 1776, houve uma lacuna de duzentos anos até a publicação do trabalho seminal de Azzi e Ehrenberg (1975), Household Allocation of Time and Church Attendance, considerado o ponto de partida da moderna pesquisa de Economia da Religião. A partir desse artigo, o fluxo de trabalhos publicados sobre Economia da Religião tem crescido sistematicamente. No espaço de tempo compreendido entre os dois estudos citados, a Economia da Religião permaneceu órfã do interesse da grande maioria dos economistas, que preferiram deixar a cargo dos pesquisadores de outras Ciências Sociais, principalmente da Sociologia, a tarefa de examinar os vínculos existentes entre religião e economia.

Excetuados alguns estudiosos como Weber (1904) e Tawney (1955), o estudo da religião foi visto durante muito tempo como antagô- 
nico à ciência. Os pressupostos da tese da secularização, baseados nos trabalhos de Weber, eram tidos como verdades inquestionáveis. Entretanto esta visão tem se alterado nos últimos anos, permitindo que a Economia da Religião se estabelecesse como disciplina autônoma, além de impulsionar de modo decisivo um novo e crescente interesse de vários estudiosos pelo tema. Atualmente, muitos pesquisadores, entre os quais sociólogos, cientistas políticos e economistas, veem a religião como um elemento importante para entender os desdobramentos históricos, políticos, sociais, e até mesmo como aspecto condicionador das forças econômicas. Compreendendo o comportamento religioso como um caso de escolha racional, esses pesquisadores têm procurado explicar tal comportamento nos níveis individual, de grupo e de mercado. Atualmente existem vários jornais dedicados ao estudo científico da religião, como Journal for the Scientific Study of Religion, Sociology of Religion, The Review of Religious Research, Social Compass e Journal of Church and State.

$\mathrm{O}$ artigo de Iannaccone - intitulado Introduction to the Economics of Religion (1998) - é referência fundamental para qualquer revisão bibliográfica em Economia da Religião. Nesse trabalho, Iannaccone fez um levantamento dos principais artigos publicados até aquela data nesse campo de estudo. Na época em que o artigo foi publicado, a Economia da Religião ainda não tinha indexação como área no Journal of Economic Literature (JEL).

Atualmente essa subárea já existe: Z12. Com a crescente importância da Economia da Religião, esta disciplina conta agora com um site de divulgação de artigos $^{1}$ e de Working Papers de pesquisadores relacionados à área.

Além da tradicional Society for the Scientific Study of Religion (cuja principal publicação é o Journal for the Scientific Study of Religion) criada em 1949, que fomenta o diálogo interdisciplinar para o estudo científico da religião entre pesquisadores da Sociologia, Ciência Política, Ciências Econômicas, dentre outros campos, existem duas

\footnotetext{
${ }^{1}$ O site é http://religionomics.com/old/erel/index.htm

${ }^{2}$ ASREC é uma associação criada com o objetivo de incentivar a pesquisa e o ensino sobre as relações entre economia e religião. A associação patrocina conferências e diversas formas de interação entre pesquisadores ligados à área em questão. CESR é a principal organização que patrocina a ASREC. Sua direção e os seus associados estão envolvidos em atividades diversas, que incluem projetos de pesquisa, workshops e outros eventos, além de um programa especial de pós-graduação ligado à área na Universidade George Mason nos EUA.
} 
outras entidades institucionais, mais recentes, criadas, nos EUA, com o objetivo de aglutinar os estudiosos das relações entre economia e religião para a promoção de estudos, pesquisas e encontros sobre o tema: São elas a ASREC - The Association for the Study of Religion, Economics, and Culture e o CESR - The Center for the Economic Study of Religion. ${ }^{2} \mathrm{Na}$ Europa, existe uma rede informal de pesquisadores dedicados ao estudo da Economia da Religião: European Network on the Economics of Religion (ENER). ${ }^{3}$ A seguir serão discutidos dois fundamentos da Economia da Religião: a Escolha Racional e a Teoria do Consumidor.

\section{Fundamentos da Economia da Religião}

Os fundamentos da Economia da Religião são quatro: a) a Teoria da Escolha Racional Religiosa; b) a Teoria do Consumidor aplicada à religião; c) o modelo de produção doméstica e de capital humano de Gary S. Becker (1964, 1695) e o modelo de produção doméstica religiosa e de capital humano religioso de Laurence Iannaccone (1984, 1990) e d) a Teoria do Mercado Religioso. Por questões de espaço, serão tratados neste trabalho apenas os dois primeiros fundamentos.

\subsection{Fundamentos: A Teoria da Escolha Racional Religiosa}

Esta subseção está baseada em Iannaccone (1997), o principal expoente da Economia da Religião, com numerosos artigos publicados em vários periódicos científicos de prestígio, o qual, com base em Becker (1976), afirma que a Economia da Religião tem como suporte, como qualquer outra área de pesquisa econômica fundamentada na Escolha Racional, três premissas básicas:

Premissa 1: Comportamento maximizador - Indivíduos agem de forma racional, comparando custos e benefícios de suas ações e escolhendo aquelas que maximizem seus benefícios; ${ }^{4}$

\footnotetext{
${ }^{3} \mathrm{O}$ endereço na web da ENER é www.ener-online.org/

${ }^{4}$ Aqui não se discutirá a vantagem filosófica de esta premissa ser afirmada em termos de utilidade, razão de troca ou de autointeresse, conforme dito em Iannaccone (1992, p.124).
} 
Premissa 2: Estabilidade das preferências - as preferências apresentadas pelos indivíduos em relação à avaliação de custos e benefícios de suas escolhas tendem a não apresentar grande variabilidade de pessoa para pessoa e também apresentam estabilidade intertemporal;

Premissa 3: Equilíbrio de mercado - as interações sociais resultam em equilíbrio, decorrente da agregação de ações individuais.

Assim, pode-se afirmar que as pessoas fazem suas escolhas religiosas como elas o fariam em qualquer situação em que se vissem confrontadas com a necessidade de fazerem quaisquer outras escolhas, avaliando custos e benefícios de modo a maximizar sua utilidade. Essas escolhas não necessitam ser irreversíveis, o que significa dizer que as pessoas, eventualmente, podem mudar suas opções religiosas ou os seus níveis de compromisso religioso ao longo do tempo. De modo semelhante a outros mercados, a liberdade que os consumidores têm de escolha impõe restrições aos produtores de religião, determinando o conteúdo das commodities religiosas, bem como a estrutura das instituições responsáveis pelo seu fornecimento. Quanto mais desregulado for o mercado religioso, mais esses efeitos serão intensos.

Das três premissas, a mais importante é a do comportamento maximizador de utilidade. Contudo, a mesma deve ser avaliada sob a ótica da busca dos modelos preditivos em, de modo simplificado, representar a complexa realidade. Nesse sentido, é uma premissa simplificadora que tem a sua utilidade na abordagem da Escolha Racional, principalmente como um dos de seus pilares na modelagem do comportamento do indivíduo. A vantagem da Escolha Racional é que esta é adequada para a construção e teste de modelos de comportamento humano.

A Escolha Racional não procura investigar a mudança de preferências, que assume serem estáveis ao longo do tempo, com base em alterações de gostos, normas ou crenças. Seu foco é a modelagem de mudanças de comportamento dos indivíduos como sendo respostas ótimas à variabilidade de circunstâncias, entre as quais alterações de preços, renda, habilidades, experiências, tecnologias, restrições de recursos, dentre outros fatores.

Essas considerações, de modo idêntico, aplicam-se ao lado da oferta, em que se presume que os fornecedores de commodities religiosas 
também buscam a maximização de sua utilidade - aderentes religiosos, recursos, auxílio governamental e outros fatores que possam promover o êxito no mercado religioso. Ainda que as organizações religiosas não procurem de modo consciente a maximização de sua utilidade, serão aquelas organizações mais eficientes que irão permanecer e crescer ao longo do tempo. Assim, tanto clérigos como instituições religiosas poderão ter suas ações modeladas como se fossem respostas ótimas a restrições e oportunidades encontradas no mercado religioso.

O conjunto de interações entre consumidores e produtores de commodities religiosas forma o mercado religioso, o qual, como qualquer outro mercado, tenderá para o equilíbrio estável. A liberdade de escolha dos consumidores restringe o comportamento dos produtores. Além disso, as preferências dos primeiros plasmam o conteúdo das commodities religiosas. Em um mercado religioso relativamente desregulado e altamente competitivo, os produtores ineficientes serão excluídos pela concorrência, dando espaço àqueles que oferecerem produtos que atendam às necessidades dos consumidores.

Também deve ser dito que a abordagem da Escolha Racional pressupõe um compromisso com os métodos e objetivos da ciência em geral, o que inclui tanto a abordagem quantitativa como qualitativa. No entanto, a prioridade é para a busca de leis comportamentais que se coadunem com os critérios da objetividade, reprodutibilidade e falseabilidade.

Os modelos de Escolha Racional possuem uma estrutura lógica interna que lhes é inerente. Os mesmos abordam os problemas da escolha religiosa da seguinte forma:

\author{
Escolha: \{ações\} \\ Maximização: \{objetivos\} \\ Sujeita a: \{restrições\}
}

O teórico da Escolha Racional, ao buscar modelar o comportamento religioso, deve estabelecer quais os objetivos do agente, de modo que o problema seja passível de tratamento analítico. No caso de um modelo genérico de predição de frequência à instituição religiosa, por exemplo, a participação religiosa pode ser representada formalmente como sendo uma função de utilidade à parte, ao passo 
que as demais atividades podem ser integradas em uma função do tipo "outras fontes de satisfação". Em contrapartida, um modelo que buscasse apreender as interações entre organizações religiosas e seus fiéis (consumidores) consideraria, em termos práticos, a pregação ou prédica religiosa como sendo a produção de uma firma e a assistência dessa pregação como o consumo. O objetivo é sempre buscar um modelo que tenha um nível de abstração que procure equilibrar generalidade e clareza teóricas, de modo a captar os detalhes mais importantes de uma realidade específica e fazer inferências preditivas que sejam passíveis de validação empírica.

Como foi dito anteriormente, o objetivo do agente é, ao fazer suas escolhas entre diferentes alternativas, maximizar os seus benefícios e minimizar seus custos. Também foi dito que as preferências ou gostos do agente permanecem estáveis ao longo do tempo. Essa premissa tem por base tanto um aspecto filosófico, ao se considerar que as conviçcões fundamentais dos seres humanos seriam semelhantes independentemente de vinculação temporal ou espacial; e também um aspecto prático, já que até agora não se teria elaborado um modelo apropriado que explique e mensure a formação dos gostos e das crenças. Dessa forma, a abordagem da Escolha Racional deve explicar as alterações no comportamento religioso humano em termos de mudanças nas restrições. Assim, da premissa de estabilidade nas preferências pode ser afirmado o seguinte corolário:

Corolário: mudanças de comportamento intertemporais são resultado de mudanças nas restrições. Diferenças no comportamento religioso entre indivíduos são consequências de diferenças nas restrições que os indivíduos enfrentam.

\subsection{Fundamentos: A Teoria do Consumidor}

A partir de um enfoque microeconômico, com base na Teoria do Consumidor, a fim de caracterizar como os consumidores se comportam relativamente à religião, pode ser dito que os indivíduos administram seus gostos e preferências com base em um limitador chamado de restrição orçamentária. Pode-se configurar um vetor de bens oriundo da fé dos indivíduos. Estes podem utilizar, assim, parte de sua riqueza e de seu tempo para atender os requisitos ou restrições de sua fé. 
Seguindo a ótica de que o consumidor escolhe o que é melhor para si, pode-se supor que este dispõe de dois tipos de cestas, representadas por $\left(\mathrm{x}_{1}, \mathrm{x}_{2}\right)$. Admitindo que os preços $\left(\mathrm{p}_{1}, \mathrm{p}_{2}\right)$ dos bens componentes destas cestas são dados e que o consumidor tenha um limite de renda, chamado de restrição orçamentária, tem-se:

$$
p_{1} x_{1}+p_{2} x_{2} \leq r
$$

Onde:

$X_{1}$ - são os bens religiosos

$X_{2}$ - são os bens seculares

$r$ - é a renda do consumidor

A inequação (1) representa o conjunto orçamentário do consumidor que, aliado a seus gostos e preferências, determinará os pontos de equilíbrio. As preferências devem atender aos pressupostos clássicos 5 estabelecidos pela Teoria Microeconômica. Assume-se que a função utilidade $U\left(x_{1}, x_{2}\right)$ é crescente em x (axioma da não saciedade), é derivável e quase-côncava. Com isso, é possível classificar três tipos básicos das preferências dos consumidores quanto aos dois tipos de bens apresentados, representados a seguir.

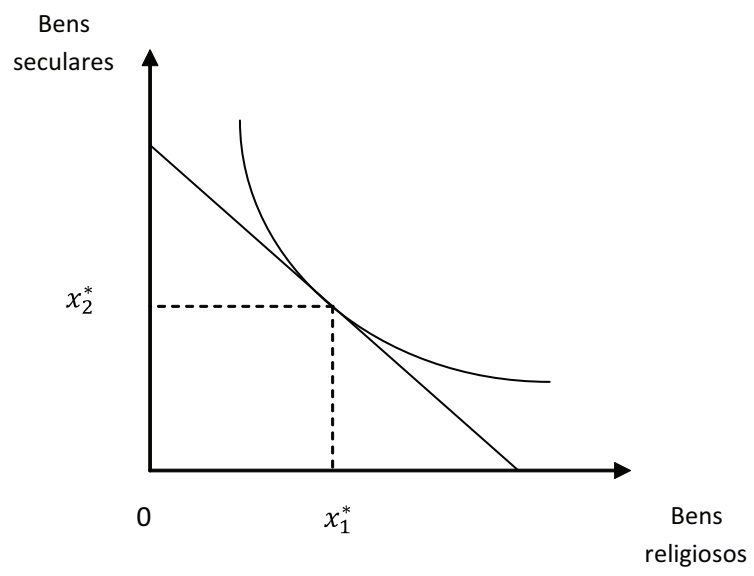

Fig. 1- Escolha Ótima de um Consumidor Religioso

Fonte: Elaboração própria

${ }^{5}$ a. Axiomas: Completa, Reflexiva e Transitiva e b. Propriedades: Monotonicidade e Convexidade. 
A Figura 1 representa os indivíduos que possuem uma religião. Estes dedicam parte de seu tempo e de sua renda ao consumo de bens religiosos e parte ao consumo de bens seculares, representados, respectivamente, pelos consumos ótimos em $X_{1}{ }^{*}$ e em $X_{2}{ }^{*}$. O consumidor religioso acredita que exista alguma taxa de marginal substituição ótima, $T M g S^{*}$, que lhe permitiria maximizar sua utilidade individual. Essa taxa teria, necessariamente, que igualar a inclinação de sua linha de restrição orçamentária, representada pela relação entre os preços dos bens religiosos e dos bens seculares, dada por $p_{1} / p_{2}$. Neste caso, temos que $T M g S^{*}=p_{1} / p_{2}$.

Essa é uma situação, conforme os dados da Tabela 1, apresentada a seguir, que representa o comportamento de, aproximadamente, $85 \%$ da população do mundo, que aloca sua renda e seu tempo para consumir bens seculares e bens religiosos.

Tabela 1- População no Mundo Segundo suas Crenças Religiosas - Ano 2005

\begin{tabular}{lcc}
\hline Religião & Total & Participação relativa (\%) \\
\hline Cristãos & 2.135 .784 .198 & 33,09 \\
Muçulmanos & 1.313 .983 .654 & 20,36 \\
Hinduístas & 870.047 .346 & 13,48 \\
Sem Religião & 768.598 .424 & 11,91 \\
Religiões Populares Chinesas & 404.922 .244 & 6,27 \\
Budistas & 378.809 .103 & 5,87 \\
Etno-Religiosos & 256.340 .652 & 3,97 \\
Ateus & 151.548 .030 & 2,35 \\
Neoreligiosos & 108.131 .713 & 1,68 \\
Sikhs & 25.373 .879 & 0,39 \\
Judeus & 15.145 .702 & 0,23 \\
Espíritas & 13.030 .538 & 0,20 \\
Baha'is & 7.614 .998 & 0,12 \\
Confucionistas & 6.470 .714 & 0,10 \\
Jainistas & 4.588 .432 & 0,07 \\
Xintoístas & 2.789 .098 & $0,0,04$ \\
Taoístas & 2.733 .859 & 0,04 \\
Zoroastristas & 2.647 .523 & 0,04 \\
Outras Religiões & 254.007 & 0,00 \\
Dupla Filiação & $(15.142 .318)$ & \\
\hline TOTAL DA POPULAÇÃo & 6.453 .671 .796 & 00 \\
\hline & & \\
\hline
\end{tabular}

Fonte: World Christian Encyclopedia, em http://worldchristiandatabase.org/

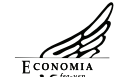


Com esses dados em mente, convém lembrar que a religião tem o potencial de influenciar e moldar, de modo decisivo e de diferentes maneiras, o comportamento humano nos aspectos individual e coletivo, contribuindo para a transformação contínua da cultura, da economia e do ambiente de todas as sociedades conhecidas.

A seguir, será representado, em termos de preferências do consumidor, um comportamento minoritário dos indivíduos, no que concerne ao consumo de bens religiosos, entre eles os ateus, que representam 2,35\% da população mundial, segundo a Tabela 1 .

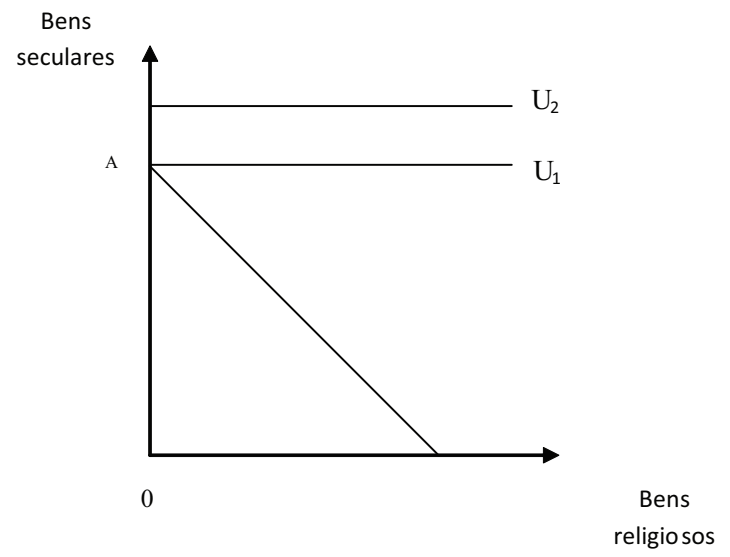

Fig. 2 - Escolha Ótima de um Consumidor Totalmente Materialista

Fonte: Elaboração própria

Representamos, na figura acima, o comportamento de um típico indivíduo sem quaisquer crenças religiosas, materialista, agnóstico ou que professa o ateísmo, o que pressupõe um consumo ótimo somente de bens seculares. Esses indivíduos têm as suas preferências moldadas de tal forma que a sua taxa marginal de substituição é nula, isto é, $T M g S^{*}=0 \forall x_{1}$, o que caracteriza o comportamento irreligioso como uma típica solução de canto, no que se refere à escolha ótima entre bens religiosos e bens seculares. Toda a renda do consumidor representado pela Figura 2 é alocada para a aquisição de bens seculares, o que está representado pelo ponto $A=x_{2}^{*}$, que é a intersecção da linha de restrição orçamentária e da curva de indiferença $U_{1}$. Caso o consumidor dispusesse de uma renda maior, consumiria mais bens seculares. Poder-se-ia perguntar sob que circunstâncias os consumidores 
representados pela Figura 2 mudariam suas preferências, passando a consumir bens religiosos. Mesmo uma queda do preço dos bens religiosos não iria modificar o perfil de consumo desses consumidores, já que, para estes, $T M g S^{*}=0 \forall x_{1}$. Neste caso, a demanda de bens religiosos, para esse tipo de consumidor, é perfeitamente inelástica em relação ao preço desses bens, isto é,

$$
\frac{\partial Q_{x 1}}{\partial P_{1}} \frac{P_{1}}{Q_{x 1}}=0 \quad \text { ou } \quad \varepsilon_{x 1}=0
$$

A única forma de um consumidor irreligioso passar a adquirir bens religiosos, relaxando o seu materialismo, ateísmo ou agnosticismo, seria pela obtenção de novas informações a que tivesse acesso, por exemplo, a de que a fé aceleraria a recuperação de doenças. De qualquer forma, somente a alteração em suas preferências e, consequentemente, em sua $T M g S$, e não a mudança nos preços relativos faria com que o consumidor irreligioso viesse a consumir bens religiosos. Já que a Teoria da Escolha Racional considera que as preferências são estáveis, pode ser predito que a conversão religiosa de indivíduos totalmente irreligiosos, ateus, agnósticos ou materialistas não será um evento comum. A seguir será representado um tipo de comportamento ainda mais restrito que o anterior, no que concerne ao consumo de bens seculares e de bens religiosos, que é o caso daqueles indivíduos cujo consumo é fortemente orientado no sentido de consumir bens religiosos.

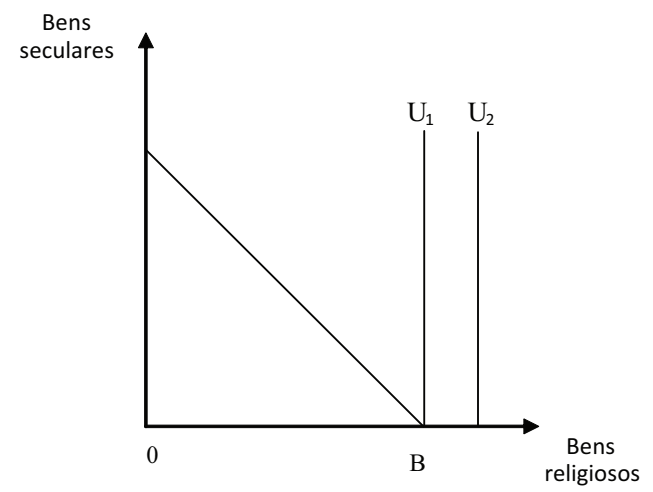

Fig. 3 - Escolha Ótima de Consumo para um Consumidor Ultrarreligioso Fonte: Elaboração própria 
A figura acima representa a escolha ótima de indivíduos que abdicam de suas posses e de bens seculares por causa de sua fé. A esses indivíduos classificamos de ultrarreligiosos, cujo consumo está concentrado em bens religiosos, o que está representado pelo ponto $B=x_{1}^{*}$. Se este tipo de consumidor tivesse um ganho em sua renda, alocaria este ganho apenas no consumo de bens religiosos.

Nesta categoria estão incluídas pessoas como o Buda Sidarta Gautama, São Francisco de Assis, Gandhi, Madre Teresa de Calcutá, dentre outros, como, por exemplo, os fiéis da Igreja Cristã primitiva, os ebionitas, ${ }^{6}$ os religiosos do movimento monaquista fundado por Santo Antão, além dos clérigos de diferentes ordens religiosas que fazem voto de pobreza. Esse caso também reflete uma escolha ótima em que a taxa marginal de substituição dos indivíduos é nula, isto é, $T M g S^{*}=0 \forall x_{2}$, o que também caracteriza uma típica solução de canto. Mesmo uma queda do preço dos bens seculares não iria alterar o perfil de consumo desses consumidores, já que, para estes, $T M g S^{*}=0 \forall x_{2}$. Neste caso, a demanda de bens seculares, para esse tipo de consumidor, também é perfeitamente inelástica em relação ao preço desses bens, isto é,

$$
\frac{\partial Q_{x 2}}{\partial P_{2}} \frac{P_{2}}{Q_{x 2}}=0 \quad \text { ou } \quad \varepsilon_{x 2}=0
$$

No caso desse tipo de consumidor, apenas novas informações que o demovessem de seu viés anti materialista poderia induzi-lo a alterar suas preferências e, consequentemente, sua $T M g S$, levando-o a adquirir bens seculares. Aqui também deve ser dito, lembrando que as preferências dos consumidores são consideradas estáveis pela Teoria da Escolha Racional, que o "esfriamento", a apostasia ou abandono da fé por um consumidor ultrarreligioso será um evento bastante incomum.

Esse tipo de indivíduo tem uma visão dualista, já que considera o mundo secular e o mundo religioso como estando separados, afirmando a necessidade de afastar-se cada vez mais do primeiro e de aproximar-se o máximo que puder do segundo. Isso porque supõe que a proximidade do mundo secular seria particularmente nociva

\footnotetext{
${ }^{6}$ Movimento judaico-cristão do primeiro século, que exaltava o desapego às posses materiais $\mathrm{e}$ defendia a observância conjunta da Lei Mosaica com as doutrinas cristãs. Além disso, consideravam que apenas os pobres poderiam ser salvos (ver V.L. Walter, in Elwell, v. 2, 1992, p. 1-2).
} 
ao seu progresso espiritual. Daí a sua preferência pelo consumo de bens religiosos e sua rejeição aos bens seculares.

O caso representado pela Figura 1 pode ser classificado como um comportamento tipicamente geral, que abrange a maioria da população do mundo. Essa conclusão pode ser deduzida da Tabela 1 , mostrada anteriormente, de onde também se conclui que o caso representado pela Figura 2, que retrata o comportamento de indivíduos irreligiosos, ateus, agnósticos ou totalmente materialistas, é minoritário. O caso da Figura 3, que representa um indivíduo que abre mão, voluntariamente, do consumo de bens seculares, apesar de poder adquiri-los, é muito mais restrito ainda, pois apenas poucos indivíduos tomam a decisão extrema de dedicar-se inteiramente à religião.

O comportamento maximizador de utilidade, ao nível do consumidor individual típico, iguala a sua $T M g S$ à sua linha de restrição orçamentária. Conforme se observem mudanças nas preferências intertemporais do consumidor, a sua $T M g S$ torna-se maior ou menor que a sua linha de restrição orçamentária. Partindo do caso padrão representado na Figura 1, conforme variem no tempo as preferências intertemporais dos indivíduos em relação à escolha dos bens seculares/religiosos, as suas respectivas taxas marginais de substituição tornam-se maiores ou menores que sua linha de restrição orçamentária. À medida que essa desigualdade se acentue, o comportamento dos indivíduos pode se aproximar de um dos dois casos extremos das soluções de canto representadas pelas Figuras 2 e 3, isto é, do puro materialismo, onde $T M g S^{*}=0 \forall x_{1}$, ou da devoção religiosa extremada, onde $T M g S^{*}=0 \forall x_{2}$.

Tem-se, assim, sob a ótica da restrição orçamentária e das preferências do consumidor, a forma como este se comporta em relação à sua espiritualidade ou religiosidade. $\mathrm{O}$ arcabouço proposto aqui não é novo e sim a determinação do espaço de atuação dos três tipos de consumidores, que representam, em seu conjunto, o comportamento da população mundial em relação ao modo de alocação do seu consumo, em que uma boa parte dessa população consome bens derivados da subjetividade da fé individual, que foram classificados como sendo bens religiosos. 


\subsection{Teste Empírico e Metodologia}

Para testar as implicações da Escolha Racional e da Teoria do Consumidor, relativamente ao comportamento religioso individual, optou-se por empregar a técnica estatística de Análise de Discriminante, complementada previamente pela Análise de Componentes Principais. As análises foram realizadas utilizando o software R-2.11.1 e, para a Análise de Discriminante, foi utilizado o pacote discrim.

A discussão a seguir será desdobrada em duas etapas: Análise dos componentes principais do modelo e Análise discriminante propriamente dita.

\section{Análise de Componentes Principais}

A análise de componentes principais toma $p$ variáveis $\mathrm{X}_{1}, \mathrm{X}_{2}, \ldots, \mathrm{X}_{\mathrm{p}}$ (6 variáveis neste trabalho) e encontra combinações lineares dessas, produzindo os componentes $\mathrm{Z}_{1}, \mathrm{Z}_{2}, \ldots, \mathrm{Z}_{\mathrm{p}}$ :

$$
Z_{i}=\alpha_{i 1} X_{1}+\alpha_{i 2} X_{2}+\cdots+\alpha_{i p} X_{p}
$$

que variam tanto possível para os indivíduos, sujeitos à condição:

$$
\alpha_{i 1}^{2}+\alpha_{i 2}^{2}+\cdots+\alpha_{i p}^{2}=1
$$

Note-se que cada componente $Z_{i}$ produz uma combinação linear das $p$ variáveis, produzindo assim um escore (chamado de escore) para cada indivíduo $i$.

Para encontrar tanto as variâncias associadas a cada componente como os coeficientes das combinações lineares, a técnica dos componentes principais lança mão da matriz de covariância das variáveis. As variâncias dos componentes principais são os autovalores dessa matriz, ao passo que os coeficientes $a_{i 1}, a_{i 2}, \ldots, a_{i p}$ são os autovetores associados. A matriz de covariância é simétrica e tem a forma:

$$
\sum=\left[\begin{array}{ccc}
c_{11} & \cdots & c_{1 p} \\
\vdots & \ddots & \vdots \\
c_{p 1} & \cdots & c_{p p}
\end{array}\right]
$$


Uma importante característica dos autovalores é que a soma desses é igual à soma dos elementos da diagonal principal da matriz de covariância, ou seja, ao traço dessa matriz:

$$
\lambda_{1}+\lambda_{2}+\cdots+\lambda_{p}=c_{11}+c_{22}+\cdots+c_{p p}
$$

Em que $\lambda_{\mathrm{i}}$ são os autovalores, ou variância, de cada um dos $i$ componentes.

A análise de componentes principais pode ser obtida através das variáveis em estudo padronizadas. Isto é, com as variáveis tendo média zero e desvio-padrão um. Neste caso, os autovetores estarão associados com a matriz:

$$
\rho=\left[\begin{array}{ccc}
1 & \cdots & \rho_{1 p} \\
\vdots & \ddots & \vdots \\
\rho_{p 1} & \cdots & 1
\end{array}\right]
$$

As combinações lineares dos componentes gerados, neste caso, são:

$$
Z_{i}=\alpha_{i 1}\left(\frac{X_{1}-\mu_{1}}{\sigma_{1}}\right)+\alpha_{i 2}\left(\frac{X_{2}-\mu_{2}}{\sigma_{2}}\right)+\cdots+\alpha_{i p}\left(\frac{X_{p}-\mu_{p}}{\sigma_{p}}\right)
$$

Observe-se que, na análise de componentes principais utilizando a matriz de correlações, a variância de cada variável não afeta os autovalores gerados, pois as variáveis estão na mesma escala, mas a estrutura de correlação entre as variáveis afeta a estimação dos pesos nos componentes. Neste trabalho, optou-se pela utilização da matriz de correlações para a criação dos escores fatoriais.

\section{Estimação da Análise de Componentes Principais}

Com o objetivo de testar as premissas da Escolha Racional Religiosa aplicadas à Teoria do Consumidor, foi utilizada a Pesquisa Social Brasileira (PESB) de 2004. Empregaram-se dados de consumo de bens seculares e da frequência religiosa, usada, em nosso caso, como proxy para o consumo de bens religiosos. Foram utilizadas seis variáveis do banco de dados da PESB que representavam o número absoluto de bens seculares de 1514 entrevistados. As variáveis selecionadas 
foram: Televisão, Walkman, Banheiro, Telefone Celular, Computador e Carro. As estatísticas descritivas das variáveis seguem a seguir:

Tabela 2 - Estatísticas Descritivas das Variáveis

\begin{tabular}{lcccccc}
\hline & Televisão & Walkman & Banheiro & Celular & Computador & Carro \\
Média & 1,41 & 1,32 & 1,29 & 0,83 & 0,21 & 0,40 \\
Desvio-Padrão & 0,89 & 0,99 & 0,72 & 1,07 & 0,47 & 0,64 \\
Mínimo & 0 & 0 & 0 & 0 & 0 & 0 \\
Máximo & 6 & 6 & 6 & 6 & 5 & 4 \\
\hline
\end{tabular}

A matriz de correlações entre estas seis variáveis utilizadas para a análise segue abaixo:

Tabela 3 - Matriz de Correlações entre as Variáveis

\begin{tabular}{lcccccc}
\hline & Televisão & Walkman & Banheiro & Celular & Computador & Carro \\
Televisão & 1 & 0,48 & 0,50 & 0,46 & 0,44 & 0,43 \\
Walkman & 0,48 & 1 & 0,33 & 0,38 & 0,37 & 0,36 \\
Banheiro & 0,50 & 0,33 & 1 & 0,41 & 0,45 & 0,49 \\
Celular & 0,46 & 0,38 & 0,41 & 1 & 0,48 & 0,47 \\
Computador & 0,44 & 0,37 & 0,45 & 0,48 & 1 & 0,46 \\
Carro & 0,43 & 0,36 & 0,49 & 0,47 & 0,46 & 1 \\
\hline
\end{tabular}

Com esta matriz foram gerados os seguintes pesos para as variáveis padronizadas:

Tabela 4 - Pesos das Variáveis Padronizadas

\begin{tabular}{lcccccc}
\hline & C1 & C2 & C3 & C4 & C5 & C6 \\
Televisão & $-0,43$ & 0,29 & $-0,34$ & $-0,38$ & $-0,25$ & $-0,64$ \\
Walkman & $-0,37$ & 0,80 & 0,06 & 0,28 & 0,21 & 0,33 \\
Banheiro & $-0,41$ & $-0,32$ & $-0,64$ & $-0,16$ & 0,02 & 0,55 \\
Celular & $-0,41$ & $-0,12$ & 0,57 & $-0,15$ & $-0,64$ & 0,26 \\
Computador & $-0,41$ & $-0,24$ & 0,39 & $-0,34$ & 0,70 & $-0,11$ \\
Carro & $-0,42$ & $-0,33$ & $-0,03$ & 0,79 & 0,00 & $-0,32$ \\
\hline
\end{tabular}

Para cada componente, temos a estimação do desvio-padrão $(\sqrt{\lambda})$ de cada um: 
Tabela 5 - Desvio -Padrão das Variáveis

\begin{tabular}{cc}
\hline Componente & Desvio-Padrão \\
1 & 1,78 \\
2 & 0,85 \\
3 & 0,78 \\
4 & 0,73 \\
5 & 0,72 \\
6 & 0,66 \\
\hline
\end{tabular}

Em seguida, vê-se a representação gráfica dos pesos de cada variável, onde se nota que o primeiro componente gerado pondera quase que homogeneamente as variáveis padronizadas. Já o segundo componente discrimina os indivíduos que possuem Televisão + Walkman dos indivíduos que tem Celular + Computador + Banheiro + Carro.

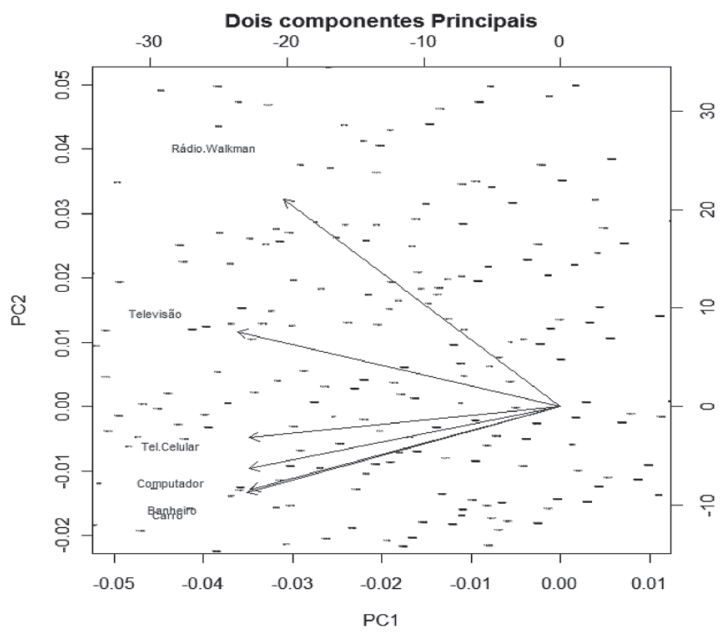

Fig. 4 - Pesos de cada variável

Fonte: Elaboração própria

$\mathrm{Na}$ presente análise, utiliza-se apenas o escore do primeiro componente que já representa 52,9\% da variabilidade total dos dados destas seis variáveis. A utilização de mais componentes não se mostrou mais eficaz. Os pesos foram multiplicados por-l. Consequentemente, a variável utilizada como proxy para consumo secular dos indivíduos é: 


$$
\begin{aligned}
Z_{i}=0,43\left(\frac{\text { Televisão }-1,41}{0,89}\right)+0,37\left(\frac{\text { Walkman }-1,32}{0,99}\right)+0,41\left(\frac{\text { Banheiro }-1,29}{0,72}\right) \\
\quad+0,41\left(\frac{\text { Celular }-0,83}{1,07}\right)+0,41\left(\frac{\text { Computador }-0,21}{0,47}\right) \\
\quad+0,42\left(\frac{\text { Carro }-0,40}{0,64}\right)
\end{aligned}
$$

\section{Análise Discriminante}

A análise discriminante permite descobrir as ligações que existem entre um caráter qualitativo a ser explicado e um conjunto de caracteres quantitativos explicativos. Também permite prever, por meio de um modelo, os valores da variável que derivam dos valores tomados pelas variáveis explicativas.

O objetivo fundamental da análise discriminante é a alocação de todos os elementos da amostra em grupos bem definidos, evitando todas as formas de superposição. Os dados de cada elemento, de cada um dos grupos são coletados e, em seguida, procura-se derivar uma função, que nada mais é que uma combinação linear, para melhor discriminar os grupos entre si. O resultado almejado é a obtenção de um conjunto único de coeficientes para cada uma das variáveis independentes e que classifique, com a máxima precisão, cada elemento observado nos grupos previamente definidos (Guimarães 2001, p.33).

A função discriminante linear tem a forma:

$$
Y_{X}=\beta_{0}+\beta_{1} X_{1}+\beta_{2} X_{2}+\beta_{3} X_{3}+\cdots+\beta_{n} X_{n}
$$

Onde:

$Y_{X}=$ Variável Dependente, reflete o valor do escore;

$\beta_{0}=$ Intercepto;

$\beta_{1}, \beta_{2}, \beta_{3} \ldots \beta_{n}=$ Pesos (coeficientes) atribuídos a cada variável;

$X_{1}, X_{2}, X_{3} \ldots X_{n}=$ Variáveis discriminantes; 
A análise discriminante utiliza as funções discriminantes para minimizar as alocações dos indivíduos, dadas as covariáveis, estabelecendo probabilidades a posteriori da alocação de cada grupo da variável qualitativa nos elementos da análise. Sejam $X_{1}$ e $X_{2}$ as variáveis observadas para cada indivíduo de cada grupo. No gráfico abaixo estão representadas as observações efetuadas:

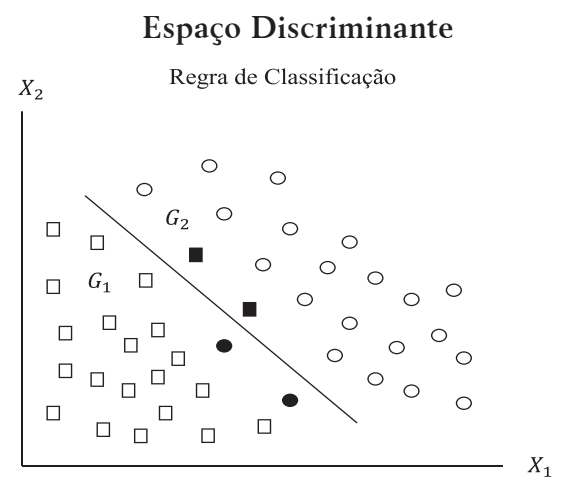

Fig. 5 - Observações Efetuadas

Fonte: Guimarães, 2000, p.33.

\section{Estimação da Análise Discriminante}

Para a análise discriminante, foram utilizadas duas variáveis quantitativas explicativas: o score de bem secular produzido pela redução da dimensão das seis variáveis descrita no capítulo anterior e uma variável de frequência religiosa discretizada e tratada com um consumo de bens religiosos. A frequência religiosa foi discretizada nos seguintes valores:

Tabela 6 - Frequência Religiosa Discretizada

\begin{tabular}{lc}
\hline Frequência Religiosa & Valor Atribuído \\
\hline Nunca & 0 \\
Raramente & 1 \\
Uma vez por ano & 1 \\
Mais de uma vez por ano & 2 \\
Uma vez por mês & 2 \\
Duas ou três vezes por mês & 3 \\
Uma vez por semana & 3 \\
Mais de uma vez por semana & 3 \\
\hline
\end{tabular}


Para a construção da variável categórica que discriminava os indivíduos da análise, fez-se uso da variável do grau de religiosidade que cada entrevistado se autoabribuiu e estratificou-se essa variável em três níveis quanto ao grau de religiosidade do entrevistado: baixo, médio e alto.

A pergunta era autoafirmativa em uma escala de 1 a 10 , sendo atribuídas as seguintes categorias:

Tabela 7 - Grau de Religiosidade Discretizada

\begin{tabular}{cc}
\hline Grau de Religiosidade & Resposta \\
\hline Baixo & 1 \\
Baixo & 2 \\
Baixo & 3 \\
Médio & 4 \\
Médio & 5 \\
Médio & 6 \\
Médio & 7 \\
Alto & 8 \\
Alto & 9 \\
Alto & 10 \\
\hline
\end{tabular}

Por consequência, o modelo a ser estimado foi o seguinte:

Grau de Reliogiosidade $=$ Consumo Secular $($ Escore $)+$ Consumo Religioso (Valor Atribuído)

As probabilidades a priori estabelecidas foram estimadas da amostra, sendo:

Tabela 8 - Probabilidades a priori

\begin{tabular}{lc}
\hline Grupo & Probabilidade \\
\hline Baixo & $12,69 \%$ \\
Médio & $45,34 \%$ \\
Alto & $41,98 \%$ \\
\hline
\end{tabular}


As médias das variáveis explicativas do modelo para cada um dos grupos são:

Tabela 9 - Médias das Variáveis Explicativas

\begin{tabular}{lcc}
\hline & \multicolumn{2}{c}{ Consumo } \\
\cline { 2 - 3 } Baixo & Religioso & Secular \\
Médio & 1,23 & 0,19 \\
Alto & 2,08 & 0,17 \\
\hline
\end{tabular}

Os coeficientes para as estimações das probabilidades a posteriori são:

Tabela 10 - Probabilidades a posteriori

\begin{tabular}{lcc}
\hline Consumo & Discriminante 1 & Discriminante 2 \\
\hline Religioso & 1,09 & $-0,18$ \\
Secular & $-0,09$ & $-0,56$ \\
\hline
\end{tabular}

As probabilidades de alocação $a$ posteriori das análises são as probabilidades que irão definir qual a devida alocação de cada indivíduo nos níveis da variável qualitativa de nível religioso podem ser calculadas e, com elas, predizer a classe do indivíduo. Do banco de dados, seguem os 6 primeiros indivíduos:

Tabela 11- Amostra de Indivíduos

\begin{tabular}{ccccc}
\hline Indivíduo & $\mathrm{P}($ Baixo $)$ & $\mathrm{P}$ (Médio) & $\mathrm{P}$ (Alto) & Classe Predita \\
\hline 1 & 0,03 & 0,49 & 0,47 & Médio \\
2 & 0,54 & 0,35 & 0,11 & Baixo \\
3 & 0,03 & 0,39 & 0,58 & Alto \\
4 & 0,03 & 0,42 & 0,55 & Alto \\
5 & 0,03 & 0,44 & 0,53 & Alto \\
6 & 0,09 & 0,46 & 0,45 & Médio \\
\hline
\end{tabular}


A comparação das análises geradas segue abaixo:

Tabela 12 - Comparação das Análises

\begin{tabular}{|c|c|c|c|c|}
\hline \multirow{5}{*}{ 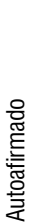 } & \multicolumn{4}{|c|}{ Estimado } \\
\hline & & Baixo & Médio & Alto \\
\hline & Baixo & 45 & 113 & 27 \\
\hline & Médio & 30 & 360 & 271 \\
\hline & Alto & 17 & 205 & 390 \\
\hline
\end{tabular}

Olhando para a Tabela 12, nota-se que a taxa de acerto foi de $54,53 \%$. Este valor é obtido dividindo-se a soma dos valores da diagonal principal pela soma total das linhas e colunas da tabela, multiplicado por 100 , ou seja, taxa de acerto $(\%)=\frac{795}{1498} \times 100 \cong 54,53 \%$. Isto é, de acordo com as premissas do modelo, considerando o consumo observado de bens seculares e de bens religiosos de um indivíduo aleatório da amostra, pode-se prever, com $54,53 \%$ de acerto, o grau de religiosidade do mesmo em uma das três categorias estabelecidas: baixa, média ou alta religiosidade.

\section{Considerações Finais: Vantagens, Críticas e Objeções à Escolha Racional}

A Teoria da Escolha Racional - como fundamento da Economia da Religião, apesar das vantagens apontadas anteriormente, como seu poder de integrar de modo sistematizado e formal premissas e hipóteses preditivas testáveis - é alvo de disputas intensas nos meios acadêmicos norte-americanos e europeus ligados ao estudo científico da religião. Anteriormente ao aparecimento do chamado "novo paradigma", a tese da secularização usufruía do monopólio quase exclusivo como paradigma teórico nas Ciências Sociais ligadas à religião, como a Sociologia e a Antropologia da Religião.

Com seu enfoque no lado da demanda para explicar a mudança religiosa e a dinâmica dos movimentos religiosos, a tese da secularização contava com o apreço indisputável, principalmente por parte dos sociólogos da religião, que atribuíam a fatores como a cultura, 
a história e à economia as alterações de gostos e preferências dos adeptos religiosos.

A Escolha Racional veio a alterar essa supremacia absoluta da tese da secularização, ao afirmar como fundamento principal suas três premissas básicas: comportamento maximizador, estabilidade das preferências religiosas, independentemente do tempo ou do lugar, e o equilíbrio no mercado religioso. Vista anteriormente como um aspecto inerentemente irracional do comportamento humano, a religião, na concepção teórica do chamado "novo paradigma", passou a ser tratada como sendo um objeto de escolha racional, como uma verdadeira commodity a ser transacionada no mercado religioso. Com essa inversão de enfoque, deslocando o eixo de explicação da dinâmica do comportamento religioso como sendo resultado das variações de oferta, no mercado religioso, por parte de organizações religiosas, e não como resultados de alterações na demanda, a Escolha Racional passou a ser vista como concorrente respeitável e séria candidata a ocupar espaços anteriormente cativos da tese da secularização. Isso pelo menos no que se refere à Europa e aos EUA, já que, fora desse eixo, as propostas do "novo paradigma" encontram pouca repercussão, como no caso da América Latina. Sobre isso comenta Frigerio (2008, p. 18):

\begin{abstract}
Comparado com o debate gerado nos Estados Unidos e na Europa, a teoria das economias religiosas proposta e defendida principalmente por Rodney Stark, Roger Finke e Larry Iannaccone tem obtido pouca atenção nos meios acadêmicos latino-americanos. Nesses, é recebida com ceticismo porque alguns de seus pressupostos despertam pouca adesão, principalmente a importância que atribui ao mercado e à Escolha Racional na dinâmica das religiões. De fato, poucos são os trabalhos locais que explicitam com precisão seus argumentos e os compreendem a partir de seus supostos e definições.
\end{abstract}

Uma das críticas à Escolha Racional é a de que não contempla as organizações religiosas que não demandam exclusividade de seus consumidores (ver Mariano, 2008, p. 57). Mas essa crítica carece de fundamento, já que um dos pressupostos da Escolha Racional religiosa é o de que "As commodities religiosas podem ser produzidas de forma coletiva, beneficiando grupos, ou de forma privada, bene- 
ficiando consumidores individualmente" (Iannaccone, 1997, p.37). A produção privada de commodities religiosas, conforme explicitado pela Economia da Religião, não exige exclusividade de seus consumidores, como no caso das religióes orientais e daquelas ligadas à Nova Era. Trabalhos como o de Miller (1995) aplicam com sucesso os conceitos da Economia da Religião a religiões orientais como Budismo e Xintoísmo, ao criar um modelo de escolha religiosa racional para o Japão.

Outra crítica é a limitação da Escolha Racional em dar conta da formação de preferências, limitações cognitivas, restrições normativas, papel desempenhado pelas emoções, interações e estruturas sociais, fatores culturais, entre outros (Iannaccone, 1995, p. 85), apontando-se a necessidade de se construir modelos mais realistas que possam abranger a complexidade e as limitações relacionadas ao ser humano.

Iannaccone (1995, p. 85) concorda que a Escolha Racional seja não realista neste sentido apontado pelos críticos, isto é, de que não abrange todos aqueles aspectos complexos anteriormente citados, embora mencione estudos ligados à Escolha Racional que buscam incorporar fatores igualmente complexos como altruísmo, inveja, dissonância cognitiva, vício, apego e autocontrole limitado (ver Iannaccone, 1984; Frank, 1985, 1988). Mas qualquer modelo teórico, de fato, é uma simplificação da realidade. Esperar que um único modelo incorpore todas as variáveis possíveis e imagináveis, ademais quando se trata de lidar, concomitantemente, com a complexidade e limitações do comportamento religioso do ser humano, parece ser algo não razoável, já que isso implicaria rendimentos decrescentes para tal modelo. Iannaccone (1995, p. 85) cita Hebert Simon, em que este afirma ser a memória de curto prazo do ser humano capaz de gravar apenas de três a sete itens para questionar a viabilidade de se construir, expandir e testar um modelo que incorpore todas as variáveis que os críticos apontam estar ausentes da Escolha Racional.

Sobre essa questão é importante a observação de Stark (in Young, 1997, p.4) sobre o questionamento da cientificidade que Karl Popper fazia a respeito de teorias que buscavam explicar todos os fenômenos de suas respectivas áreas, pela incorporação do maior número possível de variáveis. Entre essas teorias são citadas a teoria da história de Marx, a psicanálise de Freud e a psicologia individual de Alfred 
Adler. O "excesso" de capacidade explanatória destas teorias intrigava Popper, já que estas sempre se ajustavam aos dados, segundo seus defensores. Na acepção popperiana, essas teorias não eram falseáveis, portanto não poderiam ser científicas. Para Popper, uma verdadeira teoria científica deveria ser "incompatible with certain possible results of observation". Com isso, quis dizer que uma teoria científica deve predizer a observação de algumas regularidades empíricas e prever que outras não ocorrerão, por serem estas incompatíveis com as suas hipóteses. É o caso, por exemplo, da Teoria da Relatividade de Einstein, que afirmou que a luz se curvaria em consequência da gravidade, numa época em que, à exceção de Einstein e seus discípulos, ninguém acreditava nisso, o que só foi possível comprovar por testes empíricos. Segundo Stark (in Young, 1997, p.4):

Systems of thought that could accommodate all possible observations explained nothing because ahead of time they were of no predictive use - they were merely post hoc classifications schemes capable only of description or codification.

Diante das críticas, Iannaccone (1995c, p.85) afirma a vantagem da modelagem formal no fato de que esta evitaria as imprecisões, além de certos aspectos contraditórios e irrelevantes, que muitas vezes caracterizam as abordagens alternativas do comportamento religioso baseadas apenas em linguagem verbal. Nesse sentido, a clareza, a simplicidade, a concisão e o poder de integração da Teoria da Escolha Racional, evidenciados nos estudos já existentes, assim como a sua capacidade preditiva, num único arcabouço teórico, de vários aspectos relacionados ao comportamento religioso, em nível individual, de grupo e da sociedade, contariam como pontos favoráveis à utilização da Escolha Racional.

Essa vantagem tornar-se-ia mais evidente, principalmente quando se leva em consideração, conforme Iannaccone (1995, p.86), que os estudos anteriores, realizados por pesquisadores ligados a abordagens alternativas, produziram um grande volume de dados, utilizados em explicações fragmentárias em decorrência da falta de conceitos unificadores. Estas explicações negligenciaram a hipótese de racionalidade na explicação do comportamento religioso. Daí que as pesquisas realizadas sob a perspectiva da Escolha Racional tenham 
alta possibilidade de retorno em termos de capacidade explicativa, diferentemente dos retornos decrescentes que caracterizam pesquisas com enfoques alternativos para o comportamento religioso, devido ao grande número de estudos já realizados ressaltando, neste particular, o papel da pressão social, doutrinação, neurose, tradição, desvios, emoções, fatores culturais e institucionais, entre outros.

Com o seu poder unificador, a Escolha Racional propõe novas questões, métodos e hipóteses para interpretar os fatos, do passado ou do presente, ligados aos mercados religiosos, sejam estes de livre competição ou regulados pelo governo, indicando rumos para novas pesquisas. Além disso, permite, considerando a simplicidade de suas premissas, a realização de testes de hipóteses no que concerne aos determinantes da religiosidade individual, de grupo e da sociedade no que concerne à alocação de recursos escassos; aspectos ligados à conversão, mobilidade, casamento inter e intrarreligioso, compromisso e comportamento free-rider; market-share estático e dinâmico das organizações religiosas, tipologias seita-igreja, o surgimento de novos cultos, regulação governamental no mercado religioso e suas consequências, entre outros fatores.

\section{Referências}

Azzi, C., Ehrenberg, R. (1975) Household allocation of time and church attendance. Journal of Political Economy, v. 83, n.1, p. 27-56.

Becker, Gary S. (1964) Human Capital: A Theoretical and Empirical Analysis with Special Reference to Education. National Bureau of Economic Research (NBER), Nova Iorque.

(1965) A Theory Allocation of Time. Economic Journal, v. 75, n. 299, p. 493-517.

(1976) The Economic Approach to Human Behavior. University Chicago Press, Chicago.

Comte, Auguste. (2000) The Positive Philosophy (v. I, II e III). Traduzido por Harriet Martineau, Batoche Books, Ontário, Canadá [London George Bell \& Sons 1896].

Durkheim, Émile. (2001) As Formas Elementares da Vida Religiosa. Editora Paulus, segunda edição.

Elwell, Walter A. (Editor). (1990) Enciclopédia Histórico-Teológica da Igreja Cristã. Sociedade Religiosa Edições Vida Nova, São Paulo, v.2, primeira edição em português, abril.

Frank, Robert H. (1985) Choosing the Right Pond: Human Behavior and the Quest for Status. New York: Oxford University Press.

(1988) Passions Within Reason: The Strategic Role of Emotions. New York: Norton.

Freud, Sigmund. (2006) O Futuro de uma Ilusão, o Mal-Estar na Civilização e outros trabalhos (19271931). Edição Standard Brasileira das Obras Psicológicas Completas de Sigmund Freud, Editora Imago, v. 21, Rio de Janeiro. 
Frigerio, Alejandro. (2008) O paradigma da Escolha Racional: Mercado regulado e pluralismo religioso. Tempo Social. Revista de sociologia da USP, v. 20, n. 2, p. 17-39.

Guimarães, Inácio A. (2000) Construção e avaliação de uma regra de conhecimento e classificação de clientes de uma instituição financeira com base em análise multivariada. (Dissertação de Mestrado) - Universidade Federal do Paraná. Curitiba: UFPR.

Iannaccone, Laurence. R. (1984) Consumption Capital and Habit Formation with an Application to Religious Participation. Ph.D. dissertation. University of Chicago, Department of Economics.

. (1990) Religious Practice: A Human Capital Approach. Journal for the Scientific Study of Religion, v. 29, n.3, p. 297-314.

(1992) Religious Markets and the Economics of Religion. Social Compass, v. 39, n.1, p. 123-131.

. (1995) Voodoo Economics? Reviewing the Rational Choice Approach to Religion. Journal for the Scientific Study of Religion, v. 34, n.1, p. 76-89.

. (1997) Rational Choice Framework for the Scientific Study of Religion. Em: Young, Lawrence A. (Org.), Rational choice theory and religion: summary and assessment. p. 25-44, New York: Routledge.

. (1998) The Economics of Religion: A Survey of Recent Work. Journal of Economic Literature, v. 36, p.1465-1496, setembro.

Mariano, Ricardo. (2008) Usos e limites da Teoria da Escolha Racional da Religião. Tempo Social, v. 20, n.2, p. 41-66, novembro.

Miller, Alan S. (1995) A Rational Choice Model of Religious Behavior in Japan. Journal for the Scientific Study of Religion, v.34, n.2, p.234-244.

Pesquisa Social Brasileira - PESB 2004. Disponível sob consulta em: <http://www.cpdoc.fgv.br/ fgvopiniao/>. Acesso em: 02/08/2011).

Tawney, R. H. (1955) Religion and the Rise of Capitalism. Mentor Books, EUA.

Warner, Stephen. Work in progress toward a new paradigm for the sociological study of religion in the United State. American Journal of Sociology, v. 98, p.1044-1093.

Weber, Max. (2001)A Ética Protestante e o Espírito do Capitalismo. Editora Martin Claret, São Paulo [1904].

WORLD CHRISTIAN ENCYCLOPEDIA. Religions. Disponível em: $<\mathrm{http}$ //worldchristiandatabase. org/>. Acesso em: 2 de agosto de 2006.

Young, Lawrence A. (Org.), Rational choice theory and religion: summary and assessment. Routledge, New York, 1997. 